\title{
Irreversible visual loss after use of Paclitaxel
}

\section{Perda visual irreversível após uso de Paclitaxel}

Maria Helena Lopes Amigo', Paulo Falabella², Ângela Bettarello², Wagner Ghirelli²

\begin{abstract}
We describe a case of bilateral irreversible visual loss of a 64 year-old patient after prolonged use of paclitaxel. Patient presented best corrected visual acuity of 20/400 in both eyes at first visit and optical coherence tomography showed increased macular in both eyes. After six months of the interruption of -paclitaxel therapy, the patient showed slight improvement of visual acuity reaching 20/200 in both eyes, while OCT demonstrated resolution of macular edema.

Keywords: Chemotherapy/adverse effects; Paclitaxel/toxicity; Macular edema/chemically induced; Visual acuity/drug effects; Ovarian neoplasms/drug therapy; Case reports
\end{abstract}

\section{RESUMO}

Descrevemos um caso de perda visual irreversível bilateral em uma paciente de 64 anos após uso prolongado de paclitaxel. Ao exame oftalmológico apresentou acuidade visual (AV) de 20/400 em ambos os olhos (AO) na primeira consulta e tomografia de coerência óptica (TCO) evidenciando espessamento macular AO. Após seis meses da suspensão do paclitaxel, a paciente apresentava melhora discreta da AV atingindo 20/200 com correção em AO, além de TCO demostrando resolução do espessamento retiniano.

Descritores: Quimioterapia/efeitos adversos; Paclitaxel/toxicidade; Edema macular/induzido quimicamente; Acuidade visual/ efeitos de drogas; Neoplasias ovarianas/quimioterapia; Relatos de casos

1,2 Centro de Oftalmologia Tadeu Cvintal - São Paulo (SP), Brazil.

The authors declare no conflicts of interest

Received for publication 27/07/2012 - Accepted for publication 05/12/2012 


\section{INTRODUCTION}

$\mathbf{P}$ aclitaxel is a chemotherapeutic of the taxane family primarily used in the treatment of breast and ovarian cancer and in a variety of other solid tumors. Among the toxic effects are myelosuppression and peripheral neuropathy (1). There are rare cases of retinal toxicity reported in the literature, especially those culminating in visual loss due to maculopathy ${ }^{(2,3)}$.

We describe below a report of irreversible low visual acuity associated to the use of paclitaxel.

\section{Case Report}

Female patient, white, 64, came to her first appointment in February 2007 complaining of progressive low visual acuity (VA) during the last year in both eyes (BE), and was initially referred with a suspicion of cataract. She brought with her the result of an electroretinography with no changes carried out one month before the appointment, and result of nuclear magnetic resonance imaging showed ethmoid sinusitis.

She had a history of surgery for excision of ovarian cancer and chemotherapy with paclitaxel due to intestinal metastasis eighteen years ago (not knowing the dose and the medication use interval). She also reported history of facial paralysis eight months ago and left lower limb thrombosis 7 months ago.

The eye exam showed normal external eye exam and best corrected visual acuity of 20/400 ( +0.50 spherical dioptres in BE). Biomicroscopy: transparent cornea, deep anterior chamber and without inflammatory cells, iris unchanged and crystalline with mild nuclear opacity. Applanation tonometry of $20 \mathrm{mmHg}$ in BE. Fundoscopy showed signs of mild bilateral arteriosclerosis. Macula and medium periphery with physiological aspect. (Figure 1)

Fluorescein angiography exam revealed the presence of hyperfluorescence of the optic nerve and macula without extravasation signs in BE (Figure 2).

Optical coherence tomography (OCT) showed an increase in the retinal thickness with cystic spaces and aspect of sectoral retinoschisis. The right eye (RE) showed: total macular volume of $9785 \mathrm{~mm}^{3}$, and foveal thicknesses of 243 (+/-91) microns; in the left eye: total macular volume of $9415 \mathrm{~mm} 3$, and foveal thicknesses of $212(+/-41)$ microns. (Figure 3)

In April 2007 we chose to use acetazolamide oral and triamcinolone acetate $4 \mathrm{mg}$ intravitreal in the RE seeking anatomical and functional improvement, but there were no satisfactory results both in the visual acuity and retinal edema.

A literature review resulted in the location of a case report which described a bilateral cystoid macular edema secondary to the use of paclitaxel. In this case, suspending the medication led to total remission of the edema and improvement of the visual acuity after 6 weeks ${ }^{(3)}$. Therefore, we decided to interrupt chemotherapy and, after six months, the patient showed a mild improvement of the VA and reached 20/200 with correction in $\mathrm{BE}$, whereas the OCT showed complete resolution of the cystoid macular edema in BE. (Figure 4)

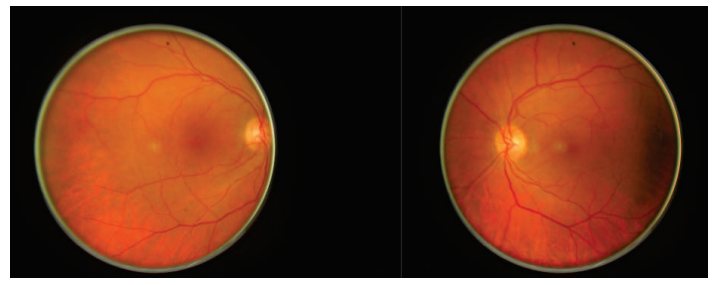

Figure 1: Retinography of both eyes (BE) showing the normal aspects of retinal macula and periphery.

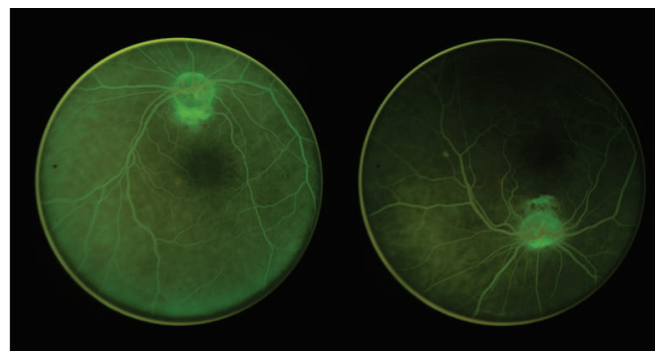

Figure 2: Retinal fluorescein angiography: hyperfluorescence in the optic nerve, and macula with no signs of extravasation in BE.
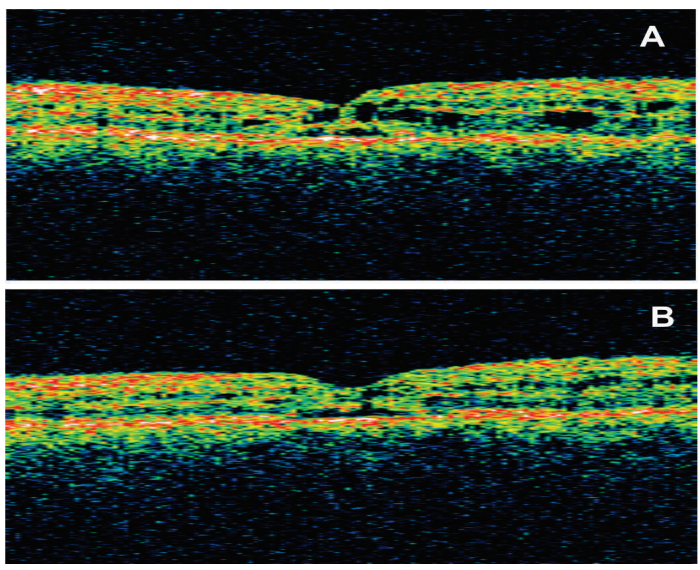

Figure3: Optical coherence tomography: Increase in the retinal thickness with cystic spaces and aspect of retinosquise in some places. Presented respectively: Total macular volume in the RE of 9785 $\mathrm{mm}^{3}$, foveal thicknesses of $243(+/-91)$ microns in the RE (A), and in the LE $9415 \mathrm{~mm}^{3}$ and $212(+/-41)$ microns in the LE (B)..
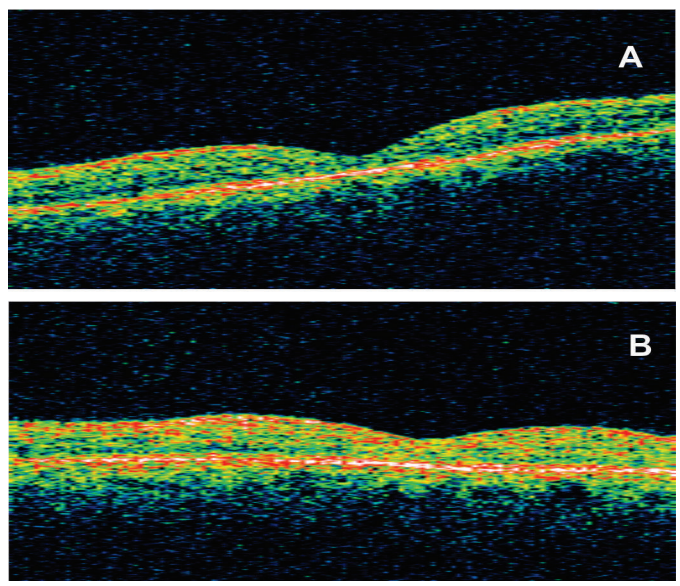

Figure 4: OCT six months after suspending the use of paclitaxel, showing retinal thickening improvement in the RE A) and LE B). 


\section{Discussion}

Ocular toxicity by paclitaxel is little known by both ophthalmologists and oncologists. It is a chemotherapeutic agent that inhibits the formation of intracellular microtubules, and whose ophthalmological side effects often include low visual acuity, scintillating scotomas and changes in evoked visual potential. Some articles have suggested the association of the drug to the onset of cystoid macular edema, but we understand this is the first one in which there was severe and irreversible loss of visual acuity, even after discontinuation of medication ${ }^{(2,3)}$.

We envisaged the differential diagnosis of cancer associated retinopathy (CAR) because of low visual acuity, which is why the electroretinography was held and the result showed no changes. Electrophysiological assessment of vision in patients treated with paclitaxel showed little correlation with visual symptoms $\mathrm{s}^{(4)}$ as in this case, being therefore further data to the diagnosis.

We highlight the important clinical characteristic related to paclitaxel toxicity and the presence of cystoid macular edema observed in the TCO associated to the absence of contrast extravasation on fluorescein angiography. This fact has been previously described for both paclitaxel and other chemotherapeutic of the taxane family, docetaxel. Toxicity to Müller cells is the theory for the pathophysiological mechanism, with subsequent accumulation of intracellular fluid and subclinical extracellular extravasation ${ }^{(3,5,6)}$.

The irreversibility of low visual acuity even after discontinuation of medication and subsequent settlement of the cystoid macular edema suggests a distinct toxicity mechanism of paclitaxel associated to permanent cell damage.
In this case report there was the relation to the use of medication, not only with the onset of macular edema, but also with the patient's irreversible visual loss, emphasizing therefore the maculotoxicity potential of paclitaxel.

\section{RefERENCES}

1. Marupudi NI, Han JE, Li KW, Renard VM, Tyler BM, BremH. Paclitaxel: a review of adverse toxicities and novel delivery strategies. Expert Opin Drug Saf. 2007; 6 (5): 609-21.

2. Hofstra LS, de Vries EG, Willemse PH. Ophthalmic toxicity following paclitaxel infusion. Ann Oncol. 1997; 8 (10): 1053.

3. Joshi MM, Garretson BR. Paclitaxel maculopathy. Arch Ophthalmol. 2007; 125 (5): 709-10.

4. Scaioli V, Caraceni A, Martini C, Curzi G, Luca G. Electrophysilogical evaluation of visual pathways in plactaxeltreated patients. J Neurooncol. 2006; 77 (1):79-87.

5. Teitelbaum BA, Tresley DJ. Cystic maculopathy with normal capillary permeability secundary to docetaxel. Optom Vis Sci. 2003; 80 (4):277-9.

6. Telander DG, Sarraf D. Cystoid macular edema with docetaxel chemotherapy and the fluid retention syndrome. Semin Ophthalmol. 2007; 22 (3): 151-3.

\section{Corresponding author:}

Wagner Ghirelli

Rua Maria Figueiredo 283

Phone No.: 1133713324

Email: iotc@secretaria.com.br 